\title{
PHYTOCHEMICAL SCREENING OF ARTOCARPUS HIRSUTUS AND ITS ANTIMICROBIAL POTENTIAL
}

\author{
SHANMUGAPRIYA K*, AKANYA S, ANDERSON CLINTON B, BERRIL NANZY S, PRAKASH PR, SUGANYA V \\ Department of Biotechnology, Dr. G R Damodaran College of Science (Autonomous), Coimbatore, Tamil Nadu, India. \\ Email: shanmugapriya8@gmail.com
}

Received: 12 February 2016, Revised and Accepted: 27 March 2017

\section{ABSTRACT}

Objective: In the present study, the effort was aimed to evaluate the phytochemical components, antioxidant activity, and antimicrobial activity of Artocarpus hirsutus fruit and leaf.

Methods: Each plant materials were extracted with two suitable solvents such as acetone and ethanol. Then, the extracts were tested for the presence of active phytoconstituents and antimicrobial activity. Then, it was subjected to antimicrobial activity against fungal and bacterial strains.

Results: The present study suggested that the selected plant extracts of $A$. hirsutus exhibit major phytoconstituents, such as alkaloids, glycosides, terpenoids, phenols, and saponins. Furthermore, the results showed that acetone fruit extract of $A$. hirsutus and ethanolic fruit extract of $A$. hirsutus exhibited significant antimicrobial activity with a maximum zone of inhibition against Staphylococcus aureus and Aspergillus tamarii.

Conclusion: The present study also exhibited remarkable antimicrobial activity against all the test microorganisms due to the presence of major bioactive phytochemicals.

Keywords: Artocarpus hirsutus, Antimicrobial, Alkaloids, Bacteria, Phytoconstituents.

(C) 2017 The Authors. Published by Innovare Academic Sciences Pvt Ltd. This is an open access article under the CC BY license (http://creativecommons. org/licenses/by/4. 0/) DOI: http://dx.doi.org/10.22159/ajpcr.2017.v10i6.17669

\section{INTRODUCTION}

Phytochemicals, isolated from the medicinal plants exhibit toxicity to microorganisms by different mechanisms. Phytochemical screening refers to the extraction, screening, and identification of the medicinally active substances found in plants. Some of the bioactive substances that are derived from plants are flavonoids, alkaloids, carotenoids, tannin, antioxidants, and phenolic compounds [1]. Phytochemicals may have biological significance, for example, carotenoids or flavonoids but are not established as essential nutrients. It is a large group of plantderived compounds hypothesized to be responsible for much of the disease protection. Different phytochemicals possess a wide range of activities that may help in protection against various diseases [2].

Phenolic content act as antioxidants as free radical scavenging, oxygen radical absorbance, and chelating of metal ions. Several phenolic studies from plant sources have reported the antioxidant and antimicrobial properties [3] in medicinal plants due to their rich phenolic compounds for the herbal medicament. The secondary metabolites play an important role in protecting the plant body from the external biotic impacts and damaging as signaling components [4]. The phenolic compounds are one of the largest and most ubiquitous groups of plant metabolites. The mechanism underlying phenolic compound toxicity to microorganisms is thought to be mediated by enzyme inhibition possibly through interaction with sulfhydryl groups and with different proteins. Phenolic compounds present in plants have gained considerable importance due to their antioxidant activities.

Flavonoids are the most diverse group of phytochemicals [5]. Flavonoids are hydroxylated phenolic substances known to be most widely distributed and synthesized natural products in plants [6]. Tannins are polymeric phenols which stimulate the immune system and are considered to have wide range of anti-infective activities [7]. They make complexes with proteins, and hence they have the ability to inactivate microbial enzymes, adhesion, and transport proteins [8].
Research on natural products with antimicrobial activity has increased significantly in recent years. Medicinal plants have been the subject of research in several countries such as Brazil [5]. This country holds a rich biodiversity and possessor of a diverse flora. In this way, the diversity of molecules found in plants makes them promising sources of new antimicrobials [9].

Diseases due to pathogenic fungi represent a critical problem to human health which is a major cause of morbidity and mortality worldwide. Widely distributed traditional medicinal plant-based antimicrobial drugs are cost effective in the treatment of infectious diseases having no side effects. Bioresources are primary (carbohydrates, proteins, and amino acids) and secondary metabolites (steroids, flavonoids, phenolics, glycosides, saponins, tannins, terpenoids, and coumarins) that impart medicinal properties to the plants [5].

Nowadays, these phytochemicals become more popular due to their countless medicinal uses. Phytochemicals play a vital role against number of diseases such as asthma, arthritis, and cancer. Unlike pharmaceutical chemicals, these phytochemicals do not have any side effects. Since the phytochemicals cure diseases without causing any harm to human beings, these can also be considered as "man-friendly medicines" [10].

Artocarpus hirsutus belongs to the Moraceae family and consists of 50 different species. It is called Hebbalasu in Kannada; Vadahar in Hindi; Lakucha, Dahu, Adahu, Iravatam, and Panasah in Sanskrit; Ranpanas and Pachpanas in Konkani; Anhili, Ayani-maram, Ayani, Anjili, and Ayiniplavu in Malayalam; Kattupula, Aiyinipala, Kurangupala, and peipala in Tamil; Pejakai in Tulu; and Adavipanasa in Telugu. A. hirsutus is a tropical evergreen tree species that is native to India (Karnataka, Kerala, Maharashtra, and Tamil Nadu) [11]. They are widely acknowledged as a rich source of bioactive secondary metabolites such as flavonoids, stilbenes, triterpenoids, and xanthones [12]. 


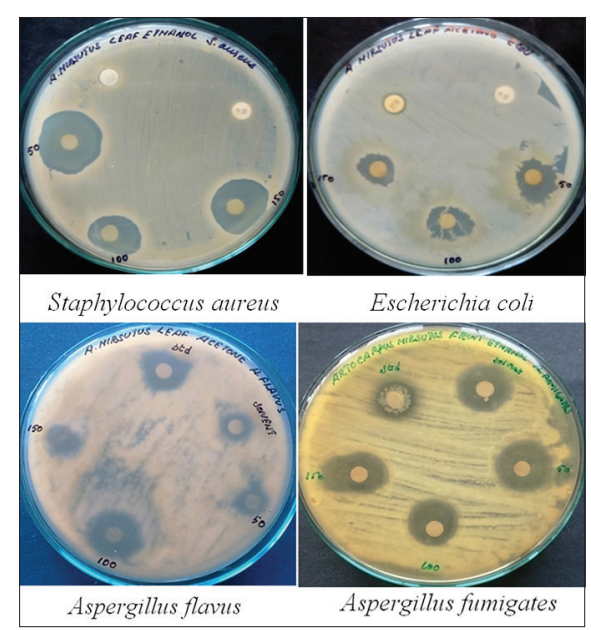

Fig. 1: Antimicrobial activity of Artocarpus hirsutus Leaf and fruit extracts on different microbial strains

The ripe fruit of $A$. hirsutus is eaten after removing the spiny outer skin. The structure of the fruit is similar to that of the much larger jackfruit. The seeds are also edible, usually fried as a snack [13]. Its bark cures diabetes, tapeworm infection, anemia, malarial fever, asthma, dermatitis, diarrhea, pimples, and ulcers. It has a long history of medicinal use in Chinese medicine, as a remedy for many kinds of diseases [14]. A. hirsutus have added a great deal in the field of phytochemistry with regard to their availability of complex phytochemical components, antibacterial activity, antihelmentic, antiinflammatory, and antiviral activity [15].

Most of the modern researches on herbal medicine have hinged around traditional medicine. The modern medicine has brought with it an array of drugs, none of which is non-toxic and quite safer for human consumption. There are hundreds of medicinal plants that have a long history of curative properties against various diseases and ailments. However, screening of plants for their activity is very essential and needs urgent attention to know the value of the plant. Hence, this medicinal plant was validated with the main objectives to screening and analyses antimicrobial activity.

\section{METHODS}

\section{Collection of samples}

The fruits and leaves of A. hirsutus were collected from Kanyakumari district in Tamil Nadu and were authenticated in Botanical Survey of India, Tamil Nadu Agricultural University (TNAU), Coimbatore. Clinical isolates were collected from Aravind Eye Hospital, Coimbatore.

\section{Preparation of plant extract}

The peel, whole fruit, and leaves of the selected plant were washed thoroughly and shade dried. The dried plant material was powdered. Then, each plant materials were extracted with two solvents such as acetone and ethanol. About $40 \mathrm{~g}$ of dried powder was suspended in $250 \mathrm{ml}$ of ethanol and acetone as solvents. The suspension was filtered using Whatman No: 1 filter paper. Then, the filtrates were centrifuged at $5000 \mathrm{rpm}$ for 5 minutes. The extracts were stored at $4^{\circ} \mathrm{C}$ for the further studies.

\section{Phytochemical screening}

All the extracts were subjected to preliminary phytochemical quanlitative and quantitative screening for the presence or absence of various primary and secondary metabolites such as test for alkaloids - Mayer's, Wager's, test for flavonoids - alkaline reagent, lead acetate, ferric chloride, test for glycosides - Borntrager, Legal's, Killers Killani, test for saponins - foam test, test for anthocyanins - Borntrager, test for tannins - 5\% $\mathrm{Fecl}_{3}$ gelatin, test for phenols - ferric chloride, test for terpenoids - Salkowski, test for carbohydrates - Molisch, Benedict, and test for leucoanthocyanin [16].

\section{Antimicrobial activity}

Antimicrobial activity of $A$. hirsutus leaf and fruit were tested against the following bacterial strains such as Escherichia coli, Staphylococcus aureus, Klebsiella spp., Enterobacter sp., and fungal strains such as Aspergillus tamarii, Aspergillus fumigates, Aspergillus flavus, and Aspergillus niger.

Antibacterial activity was carried out by standard disc diffusion method. Sterilized nutrient agar was poured aseptically into sterile petri plates and the plates were allowed to solidify at room temperature in a sterile condition. After solidification, the plates were evenly streaked with clinical sample onto the surface of the medium with a sterile cotton swab. The clinical isolates were E. coli, S. aureus, Klebsiella spp., and Enterobacter sp. The standard drug such as gentamycin was used for bacterial cultures. The antibiotic disc was placed in the agar plate using sterile forceps at one side then the paper was dipped with different concentration $(50,100$, and $150 \mu \mathrm{l})$ of plant extracts was placed on another side. Then, the bacterial plates were incubated at $28^{\circ} \mathrm{C}$ for $24 \mathrm{hrs}$ [17].

Antifungal activity was carried out by standard disc diffusion method. Sterilized potato dextrose agar was poured aseptically into sterile petri plates and the plates were allowed to solidify at room temperature in a sterile condition. After solidification, the plates were evenly streaked with clinical sample onto the surface of the medium with a sterile cotton swab. The clinical isolates were A. tamarii, A. fumigates, A. flavus, and $A$. niger. The paper was dipped with different concentration (50, 100 , and $150 \mu \mathrm{l}$ ) of plant extract was placed in an agar plate. Nystatin antibiotic was used as a control. Then, the fungal plates were incubated at $37^{\circ} \mathrm{C}$ for $24 \mathrm{hrs}[18]$.

\section{RESULTS AND DISCUSSION}

\section{Phytochemical analysis}

A. hirsutus plant is rich in major phytochemical compounds. The qualitative phytochemical analysis of fruit and leaf extract of $A$. hirsutus is presented in Table 1.

Qualitative analysis revealed the presence of alkaloids, flavonoids, glycosides, saponins, tannins, phenols, terpenoids, and carbohydrates (Table 2).

Phytochemical analysis conducted on the plant extracts revealed the presence of constituents which are known to exhibit medicinal as well as physiological activities. Analysis of the plant extracts revealed the presence of phytochemicals, such as phenols, tannins, flavonoids, saponins, glycosides, steroids, terpenoids, and alkaloids. The phenolic compounds are one of the largest and most ubiquitous groups of plant metabolites [7]. They possess biological properties such as anti-apoptosis, anti-aging, anti-carcinogen, anti-inflammation, anti-atherosclerosis, cardiovascular protection, and improvement of endothelial function, as well as inhibition of angiogenesis and cell proliferation activities. Several studies have described the antioxidant properties of medicinal plants which are rich in phenolic compounds. Natural antioxidant mainly comes from plants in the form of phenolic compounds such as flavonoid, phenolic acids, and tocopherols [19].

Flavonoids are hydroxylated phenolic substances known to be synthesized by plants in response to microbial infection and they have been found to be antimicrobial substances against a wide array of microorganisms in vitro. The plant extracts were also revealed to contain saponins which are known to produce an inhibitory effect on inflammation. They protect against hypercholesterolemia and antibiotic properties [6].

Tannins were known to possess general antimicrobial and antioxidant activities $[20,21]$. Saponins also have the property of precipitating and coagulating red blood cells. Some of the characteristics of saponins include the formation of foams in aqueous solutions, hemolytic activity, cholesterol binding properties, and bitterness [22]. Steroids have been reported to have antibacterial properties and analgesic properties [23]. 
Table 1: Qualitative phytochemical screening of $A$. hirsutus leaf and fruit extract

\begin{tabular}{|c|c|c|c|c|c|}
\hline \multirow[t]{2}{*}{ Phytochemical } & \multirow[t]{2}{*}{ Test/reagent used } & \multicolumn{2}{|l|}{ Leaf } & \multicolumn{2}{|l|}{ Fruit } \\
\hline & & Acetone & Ethanol & Acetone & Ethanol \\
\hline \multirow[t]{2}{*}{ Alkaloids } & Wagner's test & + & + & + & + \\
\hline & Mayer's test & + & + & + & + \\
\hline \multirow[t]{3}{*}{ Flavonoids } & Alkaline reagent & + & + & + & - \\
\hline & Lead acetate test & + & - & - & - \\
\hline & Ferric Chloride test & - & + & - & - \\
\hline \multirow[t]{5}{*}{ Glycosides } & Borntrager's test & + & - & + & + \\
\hline & Legal's test & + & + & + & + \\
\hline & Killani test & + & - & + & + \\
\hline & Libermann's test & + & - & + & + \\
\hline & Salkowski's test & + & + & - & + \\
\hline Saponins & Foam test & + & + & + & + \\
\hline Anthocyanins & Borntrager's test & - & - & - & - \\
\hline \multirow[t]{2}{*}{ Tannins } & $5 \% \mathrm{Fecl}_{3}$ & - & + & - & - \\
\hline & Gelatin test & + & - & + & + \\
\hline Phenols & Ferric chloride test & - & + & - & - \\
\hline \multirow[t]{2}{*}{ Carbohydrates } & Molisch's test & - & - & - & - \\
\hline & Benedict's test & + & + & - & + \\
\hline Leucoanthocyanin & Borntrager's test & - & - & - & - \\
\hline
\end{tabular}

+: Presence, -: Absent, A. hirsutus: Artocarpus hirsutus

Table 2: Quantitative phytochemical screening in A. hirsutus leaf and fruit extract

\begin{tabular}{|c|c|c|c|c|c|}
\hline \multirow[t]{3}{*}{ Assay } & \multirow[t]{3}{*}{ Concentration $(\mu \mathrm{g} / \mathrm{ml})$} & \multicolumn{4}{|c|}{ Optical density (nm) } \\
\hline & & \multicolumn{2}{|l|}{ Leaf } & \multicolumn{2}{|l|}{ Fruit } \\
\hline & & Ethanol & Acetone & Ethanol & Acetone \\
\hline \multirow[t]{3}{*}{ Total phenol content (mg/g) } & 100 & $1.91 \pm 0.02$ & $1.58 \pm 0.01$ & $1.19 \pm 0.01$ & $0.63 \pm 0.01$ \\
\hline & 200 & $2.32 \pm 0.01$ & $1.62 \pm 0.02$ & $1.39 \pm 0.01$ & $0.89 \pm 0.01$ \\
\hline & 300 & $2.61 \pm 0.01$ & $2.05 \pm 0.01$ & $1.76 \pm 0.01$ & $1.43 \pm 0.01$ \\
\hline \multirow[t]{2}{*}{ Total tannin content (mg/g) } & 100 & $1.0 \pm 0.01$ & $1.0 \pm 0.02$ & $1.06 \pm 0.01$ & $1.76 \pm 0.01$ \\
\hline & 300 & $1.8 \pm 0.01$ & $1.90 \pm 0.01$ & $1.78 \pm 0.01$ & $2.12 \pm 0.01$ \\
\hline \multirow[t]{3}{*}{ Total saponin content (mg/g) } & 100 & $0.65 \pm 0.01$ & $0.24 \pm 0.01$ & $0.26 \pm 0.01$ & $0.48 \pm 0.01$ \\
\hline & 200 & $0.98 \pm 0.01$ & $0.67 \pm 0.01$ & $0.78 \pm 0.02$ & $0.77 \pm 0.01$ \\
\hline & 300 & $1.45 \pm 0.01$ & $1.23 \pm 0.01$ & $1.14 \pm 0.01$ & $1.27 \pm 0.01$ \\
\hline \multirow[t]{3}{*}{ Total flavonoid content (mg/g) } & 100 & $1.22 \pm 0.01$ & $0.38 \pm 0.01$ & $0.57 \pm 0.01$ & $0.46 \pm 0.01$ \\
\hline & 200 & $1.30 \pm 0.01$ & $0.46 \pm 0.01$ & $0.60 \pm 0.01$ & $0.51 \pm 0.02$ \\
\hline & 300 & $1.34 \pm 0.01$ & $0.56 \pm 0.01$ & $0.63 \pm 0.01$ & $0.69 \pm 0.01$ \\
\hline \multirow[t]{2}{*}{ Total alkaloid content (mg/g) } & 100 & $0.03 \pm 0.01$ & $0.98 \pm 0.01$ & $1.40 \pm 0.01$ & $0.64 \pm 0.01$ \\
\hline & 300 & $0.55 \pm 0.01$ & $1.11 \pm 0.01$ & $1.84 \pm 0.01$ & $0.99 \pm 0.02$ \\
\hline
\end{tabular}

All the values are means of three independent determinations $\mathrm{n}=3$, analyzed in triplicate. Each value represents mean \pm SEM (n=3), one-way ANOVA was analyzed and

followed by dunnett's multiple test for mean values showed differ significantly from each other $(\mathrm{p}<0.006)$, A. hirsutus: Artocarpus hirsutus

Alkaloids have been associated with medicinal uses for centuries and one of their common biological properties is their cytotoxicity and they protect against chronic disease [24]. The results obtained in this study thus suggest the identified phytochemical compounds are the bioactive constituents and these plants are proving to be an increasingly valuable reservoir of bioactive compounds of substantial medicinal merit [25]. Traditional healing systems around the world that utilize herbal remedies are an important source for the discovery of new antibiotics [26]. Some traditional remedies have already produced compounds that are effective against antibiotic-resistant strains of bacteria [27]

\section{Determination of antimicrobial activity}

Antimicrobial activity of fruit and leaf extract of $A$. hirsutus were tested against fungal and bacterial strains. Acetone extract isolated from both leaf and fruit of $A$. hirsutus have good active antibacterial activity. It exhibited good inhibition activity against $S$. aureus, Klebsiella spp., Enterobacter sp. Acetone extract showed the maximum zone of inhibition against $S$. aureus $(55 \mathrm{~mm})$. Ethanolic extract showed low inhibition activity against bacterial strains, respectively (Fig. 1 and
Table 3). Ethanolic extract isolated from both leaf and fruit of A. hirsutus have good active antifungal activity. It exhibited good inhibition activity against $A$. tamarii, A. fumigates, A. flavus, and A. niger. Ethanolic extract showed the maximum zon e of inhibition against $A$. tamarii $(20 \mathrm{~mm})$ (Table 4).

The emergence of organisms resistant to nearly all classes of antimicrobial agents has become a serious public health concern in the past several years. It was considered as a potential source of natural or synthetic antimicrobial compounds with different molecular targets that control infections caused by microorganisms. Currently, out of eighty percentage of pharmaceuticals derived from plants, very few are being used as antimicrobials [27].

The potential in developing antimicrobials from plants lead to the development of phytomedicine to fight against pathogenic microorganisms [25]. Skin and nail infections caused by Candida sp. are one of the most common worldwide. Many researchers worked on crude plants extracts of folk medicinal plants and reported their effectiveness in controlling variety of microorganisms, worldwide. More than 10,000 
Table 3: Antibacterial activity of $A$. hirsutus leaf and fruit extract

\begin{tabular}{|c|c|c|c|c|c|c|}
\hline \multirow[t]{3}{*}{ Bacterial strains } & \multirow[t]{3}{*}{ Concentration $(\mu \mathrm{g} / \mathrm{ml})$} & \multirow[t]{3}{*}{ Standard drug } & \multicolumn{4}{|c|}{ Antimicrobial activity (zone of inhibition, mm) } \\
\hline & & & \multicolumn{2}{|l|}{ Leaf } & \multicolumn{2}{|l|}{ Fruit } \\
\hline & & & Ethanol & Acetone & Ethanol & Acetone \\
\hline \multirow{3}{*}{ Escherichia coli } & 100 & 17 & 23 & 24 & 10 & 10 \\
\hline & 200 & & 25 & 20 & 13 & 12 \\
\hline & 300 & & 27 & 18 & 30 & 27 \\
\hline \multirow{3}{*}{ Staphylococcus aureus } & 100 & 28 & 28 & 35 & 30 & 31 \\
\hline & 200 & & 20 & 32 & 22 & 50 \\
\hline & 300 & & 25 & 30 & 27 & 55 \\
\hline \multirow{3}{*}{ Klebsiella spp. } & 100 & 19 & 18 & 18 & 13 & 18 \\
\hline & 200 & & 12 & 17 & 17 & 13 \\
\hline & 300 & & 29 & 25 & 25 & 26 \\
\hline \multirow[t]{3}{*}{ Enterobacter sp. } & 100 & 12 & 17 & 10 & 7 & 15 \\
\hline & 200 & & 5 & 25 & 20 & 20 \\
\hline & 300 & & 15 & 15 & 22 & 24 \\
\hline
\end{tabular}

A. hirsutus: Artocarpus hirsutus

Table 4: Antifungal activity of $A$. hirsutus leaf and fruit extract

\begin{tabular}{|c|c|c|c|c|c|c|}
\hline \multirow[t]{3}{*}{ Fungal strains } & \multirow[t]{3}{*}{ Concentration $(\mu \mathrm{g} / \mathrm{ml})$} & \multirow[t]{3}{*}{ Standard drug } & \multicolumn{4}{|c|}{ Inhibition zone diameter in $\mathbf{m m}$} \\
\hline & & & \multicolumn{2}{|l|}{ Leaf } & \multicolumn{2}{|l|}{ Fruit } \\
\hline & & & Ethanol & Acetone & Ethanol & Acetone \\
\hline \multirow[t]{3}{*}{ A. tamarii } & 100 & 7 & 10 & 8 & 25 & 15 \\
\hline & 200 & & 10 & 5 & 14 & 13 \\
\hline & 300 & & 16 & 15 & 21 & 20 \\
\hline \multirow[t]{2}{*}{ A. fumigates } & 100 & 8 & 15 & 17 & 18 & 15 \\
\hline & 300 & & 16 & 15 & 21 & 20 \\
\hline \multirow[t]{3}{*}{ A. flavus } & 100 & 8 & 15 & 15 & 15 & 13 \\
\hline & 200 & & 13 & 10 & 17 & 12 \\
\hline & 300 & & 17 & 12 & 15 & 15 \\
\hline \multirow{3}{*}{ A. niger } & 100 & 9 & 15 & 12 & 15 & 15 \\
\hline & 200 & & 10 & 14 & 13 & 14 \\
\hline & 300 & & 14 & 10 & 15 & 13 \\
\hline
\end{tabular}

A. tamarii: Aspergillus tamarii, A. fumigates: Aspergillus fumigates, A. flavus: Aspergillus flavus, A. niger: Aspergillus niger, A. hirsutus: Artocarpus hirsutus

active secondary metabolites have been isolated and identified among Indian medicinal plants. Many phytochemical preparations with high flavonoid and saponins contents have been reported to exhibit potential antimicrobial activity against pathogenic microorganisms [17].

The present study showed the significance of A. hirsutus plant has a valuable source of secondary metabolites [17]. Further, it revealed the antimicrobial activity against the fungal and bacterial strains.

\section{CONCLUSION}

Phytochemical analysis conducted on the plant extracts revealed the presence of constituents which are known to exhibit medicinal as well as physiological activities. Analysis of the plant extracts revealed the presence of phytochemicals such as phenols, tannins, flavonoids, saponins, glycosides, steroids, terpenoids, and alkaloids. Antimicrobial activity of fruit and leaf extract of $A$. hirsutus were tested against fungal and bacterial strains. Acetone extract isolated from both leaf and fruit of $A$. hirsutus have good active antibacterial activity.

\section{ACKNOWLEDGMENTS}

The authors are grateful to the management for providing all facilities and for their encouragement.

\section{REFERENCES}

1. Pendyala V, Ramesh BJ, Vidyadhara S. Phytochemical and pharmacological evaluation of Commiphora mukul for antidepressant activity in albino mice. Asian J Pharm Clin Res 2017;10(1):360-3.
2. Shanmugapriya K, Saravana PS, Harsha P, Peer M, Binnie W. A comparative study of antimicrobial potential and phytochemical analysis of Artocarpus heterophyllus and Manilkara zapota seed extracts. J Pharm Res 2011;4(8):2587-9.

3. Olayinka AA, Okoh AI. Preliminary phytochemical screening and in vitro antioxidant activities of the aqueous extract of Helichrysum longifolium. BMC Complement Altern Med 2010;10(21):1-8.

4. Shanaida LM, Ivanusa I, Kernychna I. Phytochemical analysis of secondary metabolites of Satureja hortensis. Int J Pharm Pharm Sci 2017;9(2):315-8

5. Kumari S. Evaluation of phytochemical analysis and antioxidant and antifungal activity of Pithecellobium dulce Leaves extract. Asian J Pharm Clin Res 2017;10(1):370-5.

6. Buvaneswari K, Ramamoorthy D, Velanganni J. Preliminary phytochemical and antimicrobial activity studies on the leaves of the Indian plant Thevetia neriifolia Juss. World J Agric Sci 2011;7(6):659-66

7. Raghu V, George S, Krishna RV, Sindhu KK. Bioactive properties of phenolics present in Oroxylu mindicum - A review. J Pharmacol Phytochem 2013;2(3):23-7.

8. Patil RB, Kore BA. Phytoconstituents, pigments, gas chromatography mass spectrometry analysis, and allelopathy effect of Alternanthera ficoidea (L.) P. Beauv. Asian J Pharm Clin Res 2017;10(2):103-8.

9. Cicera NF, Heloisa HF, Maria CM, Celestina ES, Glaucia MM, Fernando GF, et al. Evaluation of the modulatory and antibacterial activity of the ethanolic extract and fractions of Duguetia furfuracea A. St. Hil. Afr J Pharm Pharmacol 2014;8(1):16-20.

10. Shanmugapriya K, Thayumanavan T. Phytochemical screening and antimicrobial potential on ethanolic extract of Gnaphalium polycaulon Pers., ethnomedicinal plant used by Nilgiri tribe from Western Ghats, Tamil Nadu, India. Med Plants Int J Phytomed Relat Ind 2016;8(2):168-71. 
11. Akhil H, Revikumar KG, Divya D. Artocarpus: A review of its phytochemistry and pharmacology. J Pharm Search 2014;9(1):7-11.

12. Anu V, Rajkumar SM, Mujeeb CA, Vinod MK. Biosynthesis of silver nanoparticles from Artocarpus hirsutus leaf extracts its antimicrobial activity and phytochemical analysis. Int $\mathrm{J}$ Res Pharm Nano Sci 2015;4(1):28-39.

13. Tang YP, Linda BL, Franz LW. Proximate analysis of Artocarpus odoratissimus (Tarap) in Brunei Darussalam. Int Food Res J 2013;20(1):409-15.

14. Madhavi Y, Bhaskar RD, Raghava RT. Studies on phytochemical analysis and antimicrobial activity of Artocarpus communis fruit latex against selected pathogenic microorganisms. Indo Am J Pharm Res 2013;3(1):1360-70.

15. Vinay SM, Venkatachalapathy R, Makari HK, Ramesh BS. Phytochemical analysis and antimicrobial activity of Artocarpus hirsutus: An in vitro study. Int J Pharm Bio Sci 2014;5(3):98-104.

16. Harborne JB. Phytochemical Methods. London: Chapman and Hall Ltd.; 1973. p. 49-188.

17. Lekshmi NC, Sumi SB, Viveka S, Brindha JR. Antibacterial activity of nanoparticles from Allium sp. J Microbiol Biotechnol Res 2012;2:115-9.

18. Lakhdar L, Farah A, Lahlou I, Rida S, Bouziane A, Ennibi O. Antibacterial effectiveness of selected moroccan essential oils against the highly virulent Jp2 clone of Aggregatibacter actinomycetemcomitans. Int J Pharm Pharm Sci 2017;9(2):47-51.

19. Tran MH, Pham VT, Do ND, Nguyen TT, Ba TC, Le TT, et al.
Antimicrobial, antioxidant activities and cytotoxicity evaluation of Artocarpus nigrifolius C.Y. Wu from Vietnam. Afr J Microbiol Res 2013;7(15):1326-31.

20. Okuda T. Systematics and health effects of chemically distinct tannins in medicinal plants. Phytochemistry 2005;66(17):2012-31.

21. Scalbert A. Antimicrobial properties of tannins. Phytochemistry 1991;30(12):3875-83

22. Jigna P, Sumitra C. Antibacterial and phytochemical studies on twelve species of Indian medicinal plants. Afr J Biomed Res 2007;10:175-81.

23. Amin MM, Sawhney SS, Jassan MM. Quantitative and qualitative analysis of phytochemicals of Taraxacum officinale. Wudpecker J Pharm Pharmacol 2013;2(1):1-5.

24. Ranganathan R, Vijayalakshmi R, Parameswari P. Ethnomedicinal survey of Jawadhu hills in Tamil Nadu. Asian J Pharm Clin Res 2012;5(2):45-9.

25. Vikrant A, Narender T, Kashyap CP. Preliminary phytochemical analysis of the extracts of Psidium leaves. J Pharmacogn Phytochem 2012;1(1):1-5.

26. Odunbaku OA, Ilusanya OA, Akasoro KS. Antibacterial activity of ethanolic leaf extract of Ficus exasperata on Escherichia coli and Staphylococcus albus. Sci Res Essay 2008;3(11):562-4.

27. Koné WM, Atindehou KK, Terreaux C, Hostettmann K, Traoré D, Dosso M. Traditional medicine in north Côte-d'Ivoire: Screening of 50 medicinal plants for antibacterial activity. J Ethnopharmacol 2004;93(1):43-9. 